\title{
Ascorbic acid and phenolic contents, antioxidant capacity and flavonoids composition of Brazilian Savannah native fruits
}

\author{
Aline Medeiros ALVES $^{1 \star}$, Tiago DIAS ${ }^{1}$, Neuza Mariko Aymoto HASSIMOTTO², Maria Margareth Veloso NAVES
}

\begin{abstract}
Brazilian Savannah native fruits have been investigated as potential sources of antioxidant substances. Cagaita, cerrado cashew and gabiroba were characterized with regard to the ascorbic acid and phenolic contents, antioxidant capacity and flavonoids composition. Gabiroba presented higher contents of ascorbic acid $\left(61.5 \mathrm{mg} .100 \mathrm{~g}^{-1}\right)$, total phenolic compounds (1,222.59 mg GAE.100 $\left.\mathrm{g}^{-1}\right)$, and antioxidant capacity (DPPH, FRAP and ORAC assays) than cagaita and cerrado cashew. The correlation coefficients between total ascorbic acid or total phenolic contents and antioxidant capacity were strong and significant $(0.970 \leq \mathrm{r} \leq 0.998)$. Quercetin derivatives were found in cagaita $\left(1.94 \mathrm{mg} .100 \mathrm{~g}^{-1}\right)$ and myricetin derivatives in cerrado cashew (1.2 mg.100 g $\left.\mathrm{g}^{-1}\right)$. Peonidin 3-glucoside was the main anthocyanin in cerrado cashew, and its flavonoids composition was first identified in this study. Gabiroba showed relevant catechin content $\left(23.32 \mathrm{mg} .100 \mathrm{~g}^{-1}\right)$. These Brazilian native fruits may be considered as important sources of bioactive compounds, notably gabiroba, since it presents high phenolic contents and antioxidant capacity.
\end{abstract}

Keywords: Cerrado; Eugenia dysenterica DC; Anacardium othonianum Rizz.; Campomanesia adamantium (Cambess.) O. Berg; flavonoids.

Practical Application: Cagaita, cerrado cashew and gabiroba can be used by the food industry as sources of natural antioxidants.

\section{Introduction}

The Brazilian Savannah, known as Cerrado, produces several native fruits, which have been investigated as potential sources of antioxidant substances (Souza et al., 2012). Cagaita (Eugenia dysenterica DC), cerrado cashew (Anacardium othonianum Rizz.) and gabiroba (Campomanesia adamantium (Cambess.) O. Berg) are used as food, as well as nutraceuticals in folk medicine, with the potential of contributing to the economy of the Cerrado. These fruits exhibit high moisture contents (Cardoso et al., 2011; Pereira et al., 2012) and substantial amounts of total phenolic compounds (Rocha et al., 2011). The literature has reported the effect of cagaita pulp on the prevention of diet-induced obese mice (Donado-Pestana et al., 2015), of cerrado cashew's leaves against ulcers and gastritis (Luiz-Ferreira et al., 2010), and of gabiroba against liver toxicity (Fernandes et al., 2015). However, the factors and mechanisms related to these effects remain unknown, as well as the phenolic composition and antioxidant potential of these native fruits.

Considering the diversity of antioxidant substances present in foods, several methods have been developed to assess the antioxidant capacity of foods. Thereby, the combination of at least two methods is recommended to provide more comprehensive results of the antioxidant capacity of fruits (López-Alarcón \& Denicola, 2013).

Reliable data regarding the content of bioactive compounds and the antioxidant capacity of fruits are important tools for public health, as the regular consumption of fruits and vegetables is associated with a reduced risk of developing cardiometabolic diseases (Cavallo et al., 2016). In addition, the information about the phytochemical contents helps to add commercial and industrial value to the fruits.

Given the importance of research on natural antioxidants and the scarcity of data related to the bioactive potential of Brazilian native fruits, the objectives of the present study were to assess the content of total ascorbic acid and phenolic compounds, to estimate and correlate the antioxidant capacity measured by different methods, and to identify and quantify the flavonoid content of the edible portions of cagaita, cerrado cashew and gabiroba.

\section{Material and methods}

\subsection{Samples}

Cagaita, cerrado cashew and gabiroba were collected in areas representing the Cerrado biome, in the central region of Goiás State, Brazil. The specimens were confirmed by the herbarium of the Federal University of Goiás (UFG). The edible parts of cagaita (peel and pulp) and cerrado cashew (pseudofruit) were extracted manually, and the edible part of gabiroba (pulp) was extracted using an industrial depulper. Thereafter, the samples were freeze dried, vacuum-sealed and stored under refrigeration and 
dim light. The moisture content of the samples was determined by drying under vacuum (Association of Official Agricultural Chemists, 2010).

\subsection{Total ascorbic acid (vitamin C) analysis}

The ascorbic acid content was extracted with metaphosphoric acid $(0.3 \%)$ and analyzed using a liquid chromatograph composed of an automatic display, quaternary pump and diode-array detector (DAD). The total ascorbic acid content was estimated after a reduction of dehydroascorbic acid with $10 \mathrm{mM}$ of dithiothreitol (Hassimotto et al., 2008). The results were expressed in $\mathrm{mg}$ of total ascorbic acid per $100 \mathrm{~g}$ of fresh weight $\left(\mathrm{mg} .100 \mathrm{~g}^{-1} \mathrm{FW}\right)$.

\subsection{Preparation of fruit extracts}

The extracts were prepared with methanol $70 \%(0.5 \mathrm{~g}$ of freeze dried sample and $25 \mathrm{~mL}$ of solvent) using a magnetic stirrer for $120 \mathrm{~min}$ at $4{ }^{\circ} \mathrm{C}$. The extracts obtained were filtered using filter paper and kept in amber glass bottles until analysis (Abe et al., 2010). These extracts were used to determine the total phenolic content and antioxidant capacity.

\subsection{Total phenolic content analysis}

The total phenolic content was analyzed according to the methodology described by Singleton \& Rossi (1965), and it was quantified using a standard curve for gallic acid (16 to $\left.100 \mathrm{mg} \cdot \mathrm{L}^{-1}\right)$. The results were expressed as mg of gallic acid equivalents (GAE) per $100 \mathrm{~g}$ of fresh weight (FW).

\subsection{Evaluation of antioxidant capacity}

The DPPH (2,2-diphenyl-1-picryl-hidrazila) radical scavenging method was carried out according to Brand-Williams et al. (1995). The ferric reducing antioxidant power (FRAP) test was conducted according to the technique described by Pulido et al. (2000). The absorption capacity of oxygen radicals (ORAC method) was analyzed as proposed by Dávalos et al. (2004). Trolox was used as the standard for the calibration curve. The results were expressed as $\mu \mathrm{mol}$ of Trolox equivalents (TE) per $\mathrm{g}$ of FW.

\subsection{Extraction and analysis of flavonoids by HPLC}

The extraction of flavonoids was performed according to the method described by Hassimotto et al. (2007). The flavonoids were analyzed using a liquid chromatograph composed of an automatic display, quaternary pump and diode-array detector (DAD). The column used was a Prodigy ODS3, $5 \mu \mathrm{m}, 250 \times 4.6 \mathrm{~mm}$ (Phenomenex Ltd., USA) at a temperature of $25{ }^{\circ} \mathrm{C}$, flow of $1 \mathrm{~mL} / \mathrm{min}$ and a running time of $45 \mathrm{~min}$. The eluted compounds were monitored at $270 \mathrm{~nm}$ and $525 \mathrm{~nm}$ (determination of anthocyanins). The flavonoids were quantified using external standards, and the identification of peaks was performed by comparison with the retention time of the commercial flavonoid standards, the absorption spectrum available in the library of the analysis system, and the mass spectra data obtained by liquid chromatography-electrospray ionization-mass spectrometry (LC-ESI-MS/MS). The results were expressed as mg aglycone per $100 \mathrm{~g}$ of FW (Hassimotto et al., 2007).

The identification of anthocyanins was carried out with an Esquires-LC mass spectrometer (MS) with an electrospray ionization (ESI) interface. HPLC run conditions were the same as described for flavonoids determination. Mass spectrometer conditions were as follows: capillary temperature of $275^{\circ} \mathrm{C}$, source voltage of $3.5 \mathrm{kV}$, positive mode for anthocyanins and negative mode for other flavonoids. The analysis was carried out using full scan from m/z 100 to 2000. The identity of flavonoids was confirmed against commercial standards.

\subsection{Statistical analysis}

The results were reported as mean and standard deviation of three replicates. One-way analysis of variance (ANOVA) followed by Tukey test was used to compare the means $(p<0.05)$. Analyses of the Pearson's correlation coefficient were performed between the ascorbic acid content or the total phenolic content and the antioxidant capacity, and between the methods used to estimate the antioxidant capacity $(p<0.05)$. The statistical calculations were performed using the Statistica software.

\section{Results and discussion}

Gabiroba showed higher ascorbic acid content than that observed in cagaita and cerrado cashew (Table 1). The total ascorbic acid content of cagaita was lower than that reported for cagaita (34.11 mg.100 g ${ }^{-1}$ ) from Minas Gerais State, Brazil (Cardoso et al., 2011). Cerrado cashew presented lower ascorbic acid content than that of the common cashew (190 mg. $100 \mathrm{~g}^{-1}$ ) (Rufino et al., 2010). The common cashew was used for comparison because no comparable data of the cerrado cashew's ascorbic acid content is available in the literature. The content of vitamin $\mathrm{C}$ in gabiroba (Table 1) is similar to that found in other tropical fruits, such as guava (66 mg.100 $\left.\mathrm{g}^{-1}\right)$ and pineapple (61 mg.100 g (Valente et al., 2011).

Regarding the total phenolic compounds (Table 1), gabiroba showed the highest phenolic contents compared to the other fruits studied, and its content is approximately 50\% higher than that observed by Malta et al. (2013) for whole gabiroba from Goiás State, Brazil (851 mg GAE.100 g $\mathrm{g}^{-1}$ ). Notably, the

Table 1. Moisture, total ascorbic acid and phenolic contents of Brazilian Savannah native fruits.

\begin{tabular}{|c|c|c|c|}
\hline \multirow{2}{*}{ Constituent } & \multicolumn{3}{|c|}{ Fruit } \\
\hline & cagaita & cerrado cashew & gabiroba \\
\hline Moisture (g.100 g-1) & $92.60 \pm 0.01^{\mathrm{a}}$ & $85.59 \pm 0.01^{b}$ & $80.87 \pm 0.04^{c}$ \\
\hline Total ascorbic acid (mg.100 g $\left.\mathrm{g}^{-1} \mathrm{FW}\right)$ & $10.63 \pm 0.05^{b}$ & $5.48 \pm 0.10^{c}$ & $61.49 \pm 0.62^{\mathrm{a}}$ \\
\hline Total phenolics (mg GAE.100 $\mathrm{g}^{-1} \mathrm{FW}$ ) & $141.95 \pm 2.12^{\mathrm{b}}$ & $160.74 \pm 6.48^{\mathrm{b}}$ & $1,222.59 \pm 40.31^{\mathrm{a}}$ \\
\hline
\end{tabular}

Significant difference (Tukey's test, $p<0.05$ ) is represented by different letters in the same row. FW: fresh weight; GAE: gallic acid equivalents. 
phenolic content of gabiroba is similar to that of fruits rich in phenolics, such as camu-camu $\left(1,176 \mathrm{mg} \mathrm{GAE} .100 \mathrm{~g}^{-1}\right)$ and Barbados cherry $\left(1,063 \mathrm{mg} \mathrm{GAE} .100 \mathrm{~g}^{-1}\right)$. It is also higher than the content observed in marolo, another native fruit from Cerrado (739 mg GAE.100 g ${ }^{-1}$ ) (Rufino et al., 2010; Souza et al., 2012). No significant difference between the values of phenolic compounds in the cagaita and cerrado cashew was observed (Table 1), and these values are in accordance with those reported in the literature (Rocha et al., 2011). The phenolic contents of cagaita and cerrado cashew were higher than those observed in cultivated fruits, such as papaya $\left(53 \mathrm{mg}\right.$ GAE. $\left.100 \mathrm{~g}^{-1}\right)$ and pineapple (38 mg GAE. $100 \mathrm{~g}^{-1}$ ) (Almeida et al., 2011).

The analysis of total phenolic compounds may be affected by the processing of the samples, the method and solvent used in the extraction, the quality of the standards, as well as the specific characteristics of each species and subspecies of the fruits (Bohn et al., 2015). These factors could explain the differences observed among the total phenolic contents of the fruits analyzed in this study and the values identified in the literature for these fruits. Despite these differences, the results indicate that these fruits are important sources of phenolic compounds, mostly gabiroba.

In the present study, three methods were performed to estimate the antioxidant capacity of the fruits due to the diversity of the antioxidant compounds of the food matrix, which can generate different results depending on the method used (López-Alarcón \& Denicola, 2013). In addition, the lack of standardization of the methods used to assess the antioxidant capacity limits the possibility of comparison between published data, also because the results are expressed in different units of concentration. For this reason and due to data scarcity about the antioxidant capacity of the fruits analyzed, other fruits were used for the discussion of our results.

The antioxidant capacity, assessed through the DPPH, FRAP and ORAC assays, showed significant variation among samples, with gabiroba exhibiting the highest capacity (Figure 1). The values observed through the DPPH for cagaita $\left(12 \mu \mathrm{mol} \mathrm{TE} . \mathrm{g}^{-1}\right)$, cerrado cashew $\left(10 \mu \mathrm{mol} \mathrm{TE} . \mathrm{g}^{-1}\right)$ and gabiroba $\left(77 \mu \mathrm{mol} \mathrm{TE} . \mathrm{g}^{-1}\right)$ were higher than those reported for other Brazilian native fruits, such as cerrado guava $\left(4 \mu \mathrm{mol} \mathrm{TE} . \mathrm{g}^{-1}\right)$ and cambuci $\left(9 \mu \mathrm{mol} \mathrm{TE} . \mathrm{g}^{-1}\right)$ (Genovese et al., 2008).

Regarding FRAP results (Figure 1), the antioxidant capacity of cagaita $\left(7.8 \mu \mathrm{mol} \mathrm{TE} . \mathrm{g}^{-1}\right)$ and cerrado cashew $\left(14 \mu \mathrm{mol} \mathrm{TE} . \mathrm{g}^{-1}\right)$ were lower than those of fruits from the Colombian Amazon, such as guava $\left(39.9 \mu \mathrm{mol} \mathrm{TE} . \mathrm{g}^{-1}\right)$ and aguaje fruit (buriti) $\left(27.8 \mu \mathrm{mol} \mathrm{TE} . \mathrm{g}^{-1}\right)$. However, the value observed for gabiroba $\left(110.2 \mu \mathrm{mol} \mathrm{TE} . \mathrm{g}^{-1}\right)$ was comparable to that of another exotic fruit, the banana-passion fruit $\left(114 \mu \mathrm{mol} \mathrm{TE} . \mathrm{g}^{-1}\right)$ (ContrerasCalderón et al., 2011).

Concerning the results obtained through the ORAC method (Figure 1), the antioxidant capacity of cagaita $\left(26.2 \mu \mathrm{mol} \mathrm{TE} . \mathrm{g}^{-1}\right)$ and cerrado cashew $\left(9.2 \mu \mathrm{mol} \mathrm{TE} . \mathrm{g}^{-1}\right)$ were lower than those of other Brazilian fruits, such as murici $\left(33.5 \mu \mathrm{mol} \mathrm{TE} . \mathrm{g}^{-1}\right)$

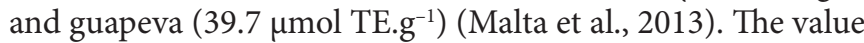
observed in gabiroba $\left(82.5 \mu \mathrm{mol} \mathrm{TE} . \mathrm{g}^{-1}\right)$ is in accordance with that reported by Malta et al. (2013) $\left(80.3 \mu \mathrm{mol} \mathrm{TE} . \mathrm{g}^{-1}\right)$.

The comparison between the results of DPPH, FRAP and ORAC showed strong and significant correlation coefficients (Figure 1). This fact suggests that these methods have similar characteristics for analysing the antioxidant capacity of cagaita, cerrado cashew and gabiroba. Candido et al. (2015) also observed a significant correlation between the results of the antioxidant capacity (through DPPH, FRAP, ORAC and ABTS) of buriti pulp (Mauritia flexuosa L.f.) from the Cerrado and Amazon biomes.

The total ascorbic acid content was positively and significantly correlated with the antioxidant capacity evaluated through all the methods used (Table 2), particularly with DPPH. Other studies using FRAP have reported a positive correlation between the ascorbic acid content and the antioxidant capacity in tropical fruits (Rufino et al., 2010) and in cashew fruit (Queiroz et al., 2011). In contrast, some studies reported a minimal or negative correlation between the vitamin $\mathrm{C}$ content and the antioxidant capacity in exotic fruits (Almeida et al., 2011; Contreras-Calderón et al.,

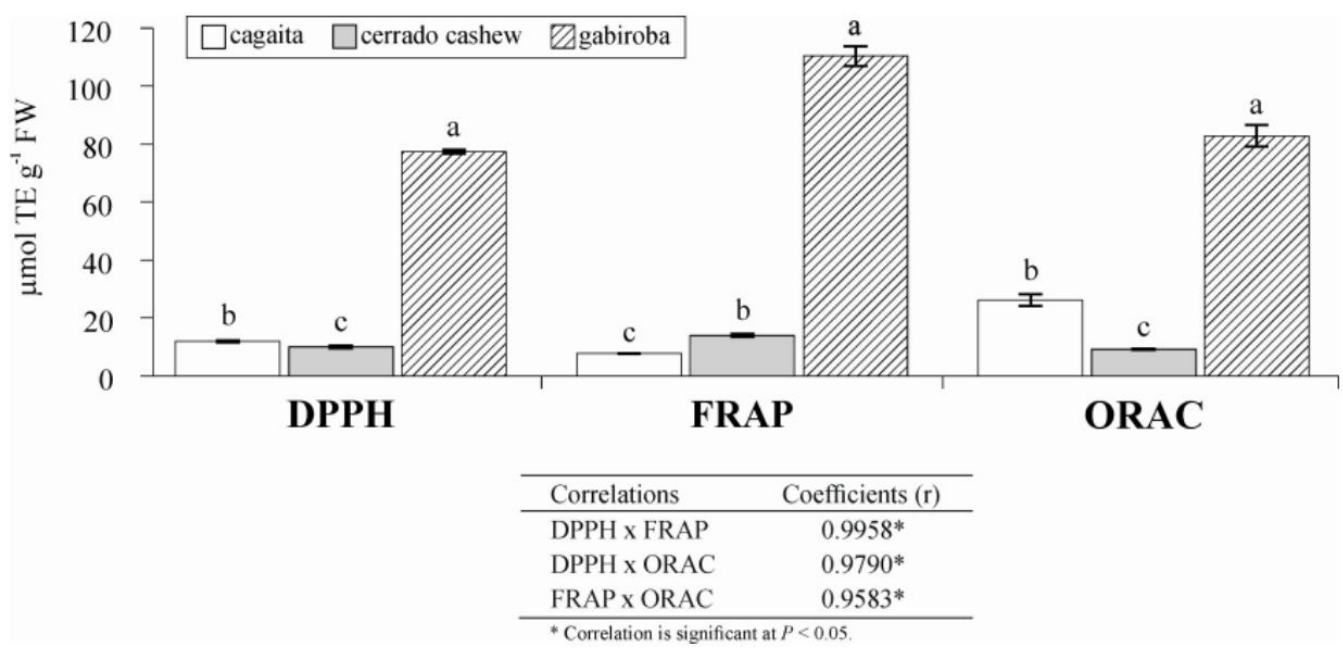

Figure 1. Antioxidant capacity of Brazilian Savannah native fruits evaluated through different methods (DPPH, FRAP and ORAC), and the Pearson's correlation coefficients between the methods. A different letter means significant difference through the Tukey's test $(p<0.05)$. 
2011). A strong correlation was also observed between the total phenolic content and the antioxidant capacity, for the three methods tested (Table 2). This correlation is reported in other studies, indicating the relevant contribution of phenolic compounds to the antioxidant capacity of fruits (Almeida et al., 2011; Celli et al., 2011; Rufino et al., 2010; Souza et al., 2012).

Several compounds are responsible for the antioxidant capacity of fruits, including certain vitamins, minerals and phenolic compounds. Flavonoids stand out among these compounds because they exhibit an increased capacity for scavenging free radicals and for chelating metal ions, thus protecting the tissues

Table 2. Significant Pearson's correlation $(p<0.05)$ between the total ascorbic acid or total phenolic contents and the antioxidant capacity (evaluated through DPPH, FRAP and ORAC) of the Brazilian Savannah native fruits.

\begin{tabular}{ccc}
\hline Parameters & Regression model & r \\
\hline TAA $x$ DPPH & $\mathrm{y}=1.2348 \mathrm{x}+1.1503$ & 0.9983 \\
TAA x FRAP & $\mathrm{y}=1.8365 \mathrm{x}-3.4803$ & 0.9896 \\
TAA $\mathrm{x}$ ORAC & $\mathrm{y}=1.2278 \mathrm{x}+7.5362$ & 0.9887 \\
TP $\mathrm{x}$ DPPH & $\mathrm{y}=0.0617 \mathrm{x}+1.7023$ & 0.9981 \\
TP $\mathrm{x}$ FRAP & $\mathrm{y}=0.0927 \mathrm{x}-3.0946$ & 0.9985 \\
TP $\mathrm{x}$ ORAC & $\mathrm{y}=0.0602 \mathrm{x}+8.6654$ & 0.9701 \\
\hline
\end{tabular}

TAA: total ascorbic acid; TP: total phenolic compounds. from oxidative damages. Flavonoids are usually found in the fruit matrix in free form (aglycones), bound to sugars (glycated) or to acyl groups, whose forms affect the quantitative determination of these compounds (Bohn et al., 2015).

Flavonoid profiles varied considerably among the fruits analyzed. Five quercetin $(\mathrm{m} / \mathrm{z} 301)$ derivatives were detected in cagaita (1.94 $\pm 0.15 \mathrm{mg}$ quercetin eq. $\left.100 \mathrm{~g}^{-1}\right)$. This value is ten times higher than that observed in commercial frozen pulp of cagaita produced in São Paulo State, Brazil (Genovese et al., 2008). The quercetin pentoside ([M-H]-, $\mathrm{m} / \mathrm{z}$ 433; MS/MS, 301) was the major flavonol (Figure 2 and Table 3 ). The quercetin content found in cagaita was lower than that detected in fruits such as Barbados cherries ( 4.1 to $5.3 \mathrm{mg} .100 \mathrm{~g}^{-1}$ ), apples (3.7 to $7.5 \mathrm{mg} .100 \mathrm{~g} \mathrm{~g}^{-1}$ ) and Brazilian cherries (5.5 to $6.2 \mathrm{mg} .100 \mathrm{~g}^{-1}$ ) (Hoffmann-Ribani et al., 2009).

Two myricetin derivatives were detected in cerrado cashew $\left(1.20 \pm 0.07 \mathrm{mg}\right.$ myricetin eq. $\left.100 \mathrm{~g}^{-1}\right)$ (Figure 2 and Table 3 ). The anthocyanins composition $\left(0.83 \pm 0.04 \mathrm{mg}\right.$ peonidin eq. $\left.100 \mathrm{~g}^{-1}\right)$ of the cerrado cashew was represented by four aglycones: cyanidin $(\mathrm{m} / \mathrm{z} 287)$, delphinidin ( $\mathrm{m} / \mathrm{z} 317)$, pelargonidin $(\mathrm{m} / \mathrm{z} 271)$ and peonidin $(\mathrm{m} / \mathrm{z} 301)$. The major anthocyanin was identified as peonidin 3-glucoside with $[\mathrm{M}]+$ at $\mathrm{m} / \mathrm{z} 463$ and MS/MS fragment at $\mathrm{m} / \mathrm{z} 301[\mathrm{M}-162]+$ (Figure 2 and Table 4 ). It is worth adding that this is the first study to identify and quantify the flavonoid content of the cerrado cashew.
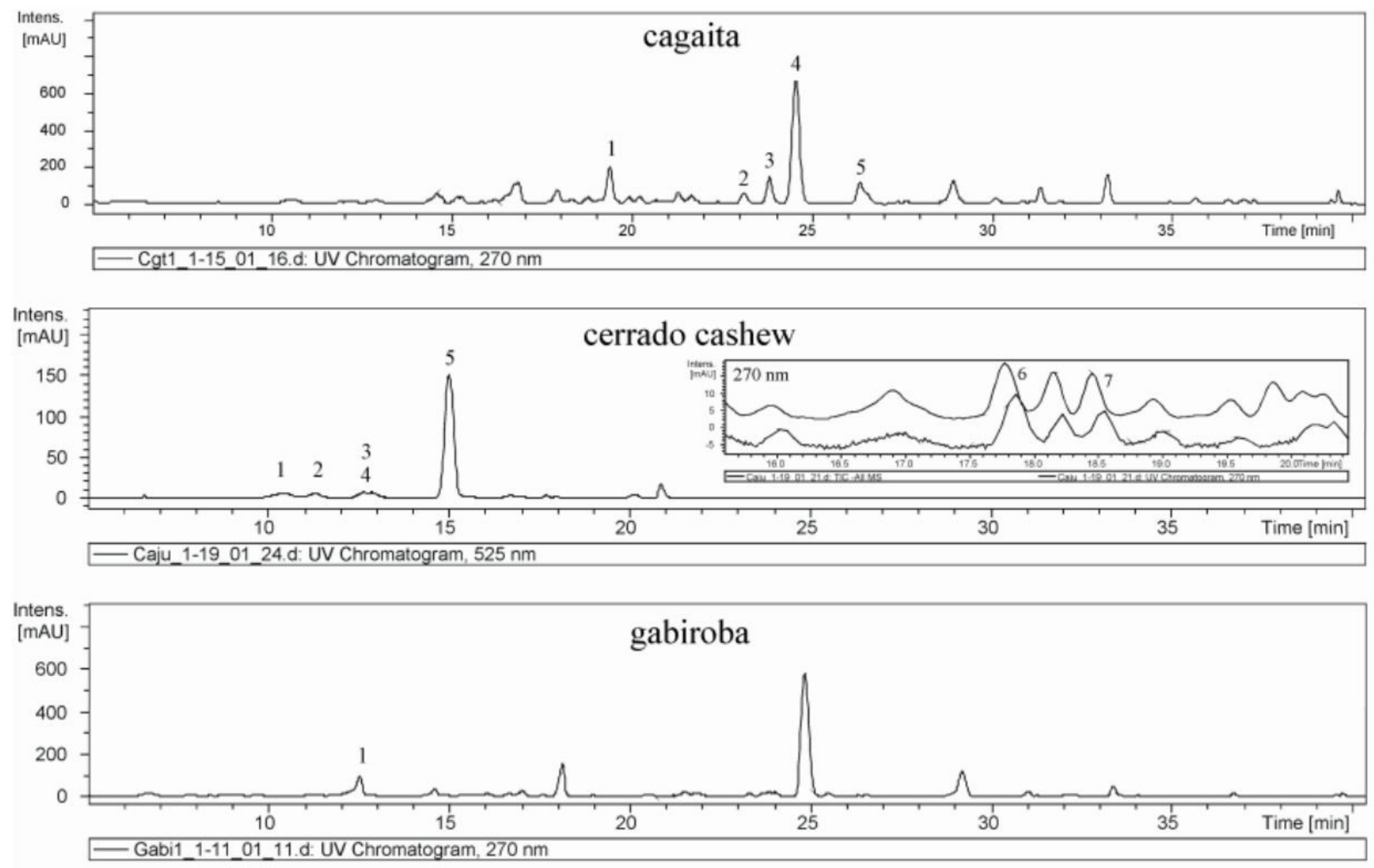

Figure 2. Chromatogram obtained by HPLC of flavonoids from cagaita, cerrado cashew and gabiroba (270 nm), and of anthocyanins from cerrado cashew $(525 \mathrm{~nm})$. The identified peaks and correspondent compounds are described in Tables 3 and 4. 
Table 3. Identification of flavonoids of the Brazilian Savannah native fruits (cagaita, cerrado cashew and gabiroba) by using LC-ESI-MS/MS (Negative mode).

\begin{tabular}{|c|c|c|c|c|}
\hline $\begin{array}{c}\text { Fruit/chromatogram peak } \\
\text { (Figure 2) }\end{array}$ & $\mathrm{RT}^{\mathrm{a}}(\mathbf{m i n})$ & {$[\mathbf{M}-\mathbf{H}]-(\mathbf{m} / \mathbf{z})$} & MS/MS & Compound \\
\hline \multicolumn{5}{|l|}{ Cagaita } \\
\hline 1 & 19.4 & 615 & $463 / 301 / 178$ & Quercetin derivative \\
\hline 3 & 23.7 & 435 & $301 / 178$ & Quercetin derivative \\
\hline 4 & 24.5 & 433 & $301 / 178$ & Quercetin pentoside \\
\hline 6 & 17.9 & 625 & $317 / 178$ & Myricetin rutinoside \\
\hline 7 & 18.5 & 631 & $317 / 178$ & Myricetin derivative \\
\hline \multicolumn{5}{|l|}{ Gabiroba } \\
\hline 1 & 12.8 & 289 & $245 / 205$ & Catechin $^{\mathrm{b}}$ \\
\hline
\end{tabular}

${ }^{\mathrm{a}} \mathrm{RT}$ : retention time; ${ }^{\mathrm{b}}$ Identity confirmed against commercial standard.

Table 4. Identification of anthocyanins of cerrado cashew by using LC-ESI-MS/MS (Positive mode).

\begin{tabular}{|c|c|c|c|c|}
\hline $\begin{array}{c}\text { Chromatogram peak } \\
\text { (Figure 2) }\end{array}$ & $\mathrm{RT}^{\mathrm{a}}(\min )$ & MS $(\mathbf{m} / \mathbf{z})$ & MS/MS & Compound \\
\hline 1 & 10.4 & 449 & 287 & Cyanidin hexoside \\
\hline 2 & 11.3 & 449 & 287 & Cyanidin 3-glucoside ${ }^{\mathrm{b}}$ \\
\hline 4 & 12.9 & 433 & 271 & Pelargonidin hexoside \\
\hline 5 & 15.1 & 463 & 301 & Peonidin 3-glucoside ${ }^{b}$ \\
\hline
\end{tabular}

${ }^{a}$ RT: retention time; ${ }^{b}$ Identity confirmed against commercial standard.

Catechin $\left(23.32 \pm 1.64 \mathrm{mg} .100 \mathrm{~g}^{-1}\right)$ was detected only in gabiroba (Figure 2 and Table 3 ). The substantial content of catechin found in gabiroba could be associated with its higher antioxidant capacity than those of cagaita and cerrado cashew. Studies have demonstrated that catechin has anti-inflammatory, antioxidant, cardioprotective and anticancer properties (Afzal et al., 2015; Shahid et al., 2016). These evidences stimulate the usual consumption of food sources of catechin, such as gabiroba. However, in vivo studies are required to confirm the in vitro antioxidant capacity of gabiroba by investigating its health benefits and related mechanisms (Fernandes et al., 2015; Giampieri et al., 2014).

The results of this study highlight the importance of Brazilian Savannah native fruits as relevant sources of natural antioxidants for healthy diets and for the food industry. Nevertheless, additional studies are necessary to increase the productivity of these fruits and their availability in the market.

\section{Conclusions}

Brazilian Savannah native fruits - cagaita, cerrado cashew and gabiroba - represent sources of ascorbic acid and phenolic compounds, with important antioxidant capacity. The flavonoids composition of cerrado cashew, with peonidin 3-glucoside as its main anthocyanin, is an unprecedented result in the literature. Gabiroba (C. adamantium) stands out from other fruits due to its relevant contents of vitamin $\mathrm{C}$ and phenolic compounds, particularly catechin, and its potential health benefits.

\section{Acknowledgements}

The authors are grateful to Capes, CNPq and UFG for financial support, and Dr. Ronaldo Veloso Naves, from the School of Agronomy/UFG, for his assistance on the fruit collection. They would also like to thank Dr. Ernani Pinto Jr. and Dr. Felipe Augusto Dörr, from the Faculty of Pharmaceutical Sciences/USP, for carrying out the mass spectrometry analysis.

\section{References}

Abe, L. T., Lajolo, F. M., \& Genovese, M. I. (2010). Comparison of phenol content and antioxidant capacity of nuts. Ciência e Tecnologia de Alimentos, 30, 254-259. http://dx.doi.org/10.1590/ S0101-20612010000500038.

Afzal, M., Safer, A. M., \& Menon, M. (2015). Green tea polyphenols and their potential role in health and disease. Inflammopharmacology, 23(4), 151-161. PMid:26164000. http://dx.doi.org/10.1007/s10787015-0236-1.

Almeida, M. M. B., Sousa, P. H. M., Arriaga, A. M. C., Prado, G. M., Magalhães, C. E. C., Maia, G. A., \& Lemos, T. L. G. (2011). Bioactive compounds and antioxidant activity of fresh exotic fruits from northeastern Brazil. Food Research International, 44(7), 2155-2159. http://dx.doi.org/10.1016/j.foodres.2011.03.051.

Association of Official Agricultural Chemists. (2010). Official methods of the Association of the Agricultural Chemists (1094 p.). Washington: AOAC.

Bohn, T., McDougall, G. J., Alegría, A., Alminger, M., Arrigoni, E., Aura, A., Brito, C., Cilla, A., El, S., Karakaya, S., Martínez-Cuesta, 
M., \& Santos, C. (2015). Mind the gap-deficits in our knowledge of aspects impacting the bioavailability of phytochemicals and their metabolites-a position paper focusing on carotenoids and polyphenols. Molecular Nutrition \& Food Research, 59(7), 1307 1323. PMid:25988374. http://dx.doi.org/10.1002/mnfr.201400745.

Brand-Williams, W., Cuvelier, M. E., \& Berset, C. (1995). Use of a free radical method to evaluate antioxidant activity. $L W T$ - Food Science and Technology (Campinas.), 28(1), 25-30. http://dx.doi.org/10.1016/ S0023-6438(95)80008-5.

Candido, T. L. N., Silva, M. R., \& Agostini-Costa, T. S. (2015). Bioactive compounds and antioxidant capacity of buriti (Mauritia flexuosa L.f.) from the Cerrado and Amazon biomes. Food Chemistry, 177, 313-319. PMid:25660891. http://dx.doi.org/10.1016/j.foodchem.2015.01.041.

Cardoso, L. M., Martino, H. S. D., Moreira, A. V. B., Ribeiro, S. M. R., \& Pinheiro-Sant'ana, H. M. (2011). Cagaita (Eugenia dysenterica DC.) of the Cerrado of Minas Gerais, Brazil: physical and chemical characterization, carotenoids and vitamins. Food Research International, 44(7), 2151-2154. http://dx.doi.org/10.1016/j.foodres.2011.03.005.

Cavallo, D. N., Horino, M., \& McCarthy, W. J. (2016). Adult intake of minimally processed fruits and vegetables: associations with cardiometabolic disease risk factors. Journal of the Academy of Nutrition and Dietetics, 116(9), 1387-1394. PMid:27174619. http:// dx.doi.org/10.1016/j.jand.2016.03.019.

Celli, G. B., Pereira-Netto, A. B., \& Beta, T. (2011). Comparative analysis of total phenolic content, antioxidant activity, and flavonoids profile of fruits from two varieties of Brazilian cherry (Eugenia uniflora L.) throughout the fruit developmental stages. Food Research International, 44(8), 2442-2451. http://dx.doi.org/10.1016/j.foodres.2010.12.036.

Contreras-Calderón, J., Calderón-Jaimes, L., Guerra-Hernández, E., \& García-Villanova, B. (2011). Antioxidant capacity, phenolic content and vitamin $\mathrm{C}$ in pulp, peel and seed from 24 exotic fruits from Colombia. Food Research International, 44(7), 2047-2053. http:// dx.doi.org/10.1016/j.foodres.2010.11.003.

Dávalos, A., Gómez-Cordovés, C., \& Bartolomé, B. (2004). Extending applicability of the Oxygen Radical Absorbance (ORAC) assay. Journal of Agricultural and Food Chemistry, 52(1), 48-54. PMid:14709012. http://dx.doi.org/10.1021/jf0305231.

Donado-Pestana, C. M., Belchior, T., \& Genovese, M. I. (2015). Phenolic compounds from cagaita (Eugenia dysenterica DC.) fruit prevent body weight and fat mass gain induced by a high-fat, high-sucrose diet. Food Research International, 77, 177-185. http://dx.doi.org/10.1016/j. foodres.2015.06.044.

Fernandes, T. O., Ávila, R. I., Moura, S. S., Ribeiro, G. A., Naves, M. M. V., \& Valadares, M. C. (2015). Campomanesia adamantium (Myrtaceae) fruits protect HEPG2 cells against carbon tetrachloride-induced toxicity. Toxicology Reports, 2, 184-193. http://dx.doi.org/10.1016/j. toxrep.2014.11.018.

Genovese, M. I., Pinto, M. S., Gonçalves, A. E. S. S., \& Lajolo, F. M. (2008). Bioactive compounds and antioxidant capacity of exotic fruits and commercial frozen pulps from Brazil. Food Science \& Technology International, 14(3), 207-214. http://dx.doi. org/10.1177/1082013208092151.

Giampieri, F., Alvarez-Suarez, J. M., \& Battino, M. (2014). Strawberry and human health: effects beyond antioxidant activity. Journal of Agricultural and Food Chemistry, 62(18), 3867-3876. PMid:24450925. http://dx.doi.org/10.1021/jf405455n.

Hassimotto, N. M. A., Genovese, M. I., \& Lajolo, F. M. (2007). Identification and characterisation of anthocyanins from wild mulberry (Morus nigra L.) growing in Brazil. Food Science \& Technology International, 13(1), 17-25. http://dx.doi.org/10.1177/1082013207075602.

Hassimotto, N. M. A., Mota, R. V., Cordenunsi, B. R., \& Lajolo, F. M. (2008). Physico-chemical characterization and bioactive compounds of blackberry fruits (Rubus sp.) grown in Brazil. Ciência e Tecnologia de Alimentos, 28(3), 702-708. http://dx.doi.org/10.1590/S010120612008000300029.

Hoffmann-Ribani, R., Huber, L. S., \& Rodriguez-Amaya, D. B. (2009). Flavonols in fresh and processed Brazilian fruits. Journal of Food Composition and Analysis, 22(4), 263-268. http://dx.doi.org/10.1016/j. jfca.2008.12.004.

López-Alarcón, C., \& Denicola, A. (2013). Evaluating the antioxidant capacity of natural products: a review on chemical and cellular-based assays. Analytica Chimica Acta, 763, 1-10. PMid:23340280. http:// dx.doi.org/10.1016/j.aca.2012.11.051.

Luiz-Ferreira, A., Almeida, A. N. A., Cola, M., Barbastefano, V., Almeida, A. B. A., Batista, L. M., Farias-Silva, E., Pellizzon, C. H., HirumaLima, C. A., Santos, L. C., Vilegas, W., \& Brito, A. R. M. S. (2010). Mechanisms of the gastric antiulcerogenic activity of Anacardium humile St. Hil on ethanol-induced acute gastric mucosal injury in rats. Molecules (Basel, Switzerland), 15(10), 7153-7166. PMid:20953159. http://dx.doi.org/10.3390/molecules15107153.

Malta, L. G., Tessaro, E. P., Eberlin, M., Pastore, G. M., \& Liu, R. H. (2013). Assessment of antioxidant and antiproliferative activities and the identification of phenolic compounds of exotic Brazilian fruits. Food Research International, 53(1), 417-425. http://dx.doi. org/10.1016/j.foodres.2013.04.024.

Pereira, M. C., Steffens, R. S., Jablonski, A., Hertz, P. F., Rios, A. O., Vizzotto, M., \& Flôres, S. H. (2012). Characterization and antioxidant potential of Brazilian fruits from the Myrtaceae family. Journal of Agricultural and Food Chemistry, 60(12), 3061-3067. PMid:22397467. http://dx.doi.org/10.1021/jf205263f.

Pulido, R., Bravo, L., \& Saura-Calixto, F. (2000). Antioxidant activity of dietary as determined by a modified ferric reducing/antioxidant power assay. Journal of Agricultural and Food Chemistry, 48(8), 3396-3402. PMid:10956123. http://dx.doi.org/10.1021/jf9913458.

Queiroz, C., Lopes, M. L. M., Fialho, E., \& Valente-Mesquita, V. L. (2011). Changes in bioactive compounds and antioxidant capacity of fresh-cut cashew apple. Food Research International, 44(5), 14591462. http://dx.doi.org/10.1016/j.foodres.2011.03.021.

Rocha, W. S., Lopes, R. M., Silva, D. B., Vieira, R. F., Silva, J. P., \& AgostiniCosta, T. S. (2011). Total phenolics and condensed tannins in native fruits from Brazilian savana. Revista Brasileira de Fruticultura, 33(4), 1215-1221. http://dx.doi.org/10.1590/S0100-29452011000400021.

Rufino, M. S. M., Alves, R. E., Brito, E. S., Pérez-Jiménez, J., SauraCalixto, F., \& Mancini-Filho, J. (2010). Bioactive compounds and antioxidant capacities of 18 non-traditional tropical fruits from Brazil. Food Chemistry, 121(4), 996-1002. http://dx.doi.org/10.1016/j. foodchem.2010.01.037.

Shahid, A., Ali, R., Ali, N., Hasan, S. K., Bernwal, P., Afzal, S. M., Vafa, A., \& Sultana, S. (2016). Modulatory effects of catechin hydrate against genotoxicity, oxidative stress, inflammation and apoptosis induced by benzo(a)pyrene in mice. Food and Chemical Toxicology, 92, 64-74. PMid:27020533. http://dx.doi.org/10.1016/j.fct.2016.03.021.

Singleton, V. L., \& Rossi, J. A. (1965). Colorimetry of total phenolics with phosphomolybidic-phosphotungstic acid reagent. American Journal of Enology and Viticulture, 16, 144-158.

Souza, V. R., Pereira, P. A. P., Queiroz, F., Borges, S. V., \& Carneiro, J. D. S. (2012). Determination of bioactive compounds, antioxidant activity and chemical composition of Cerrado Brazilian fruits. Food Chemistry, 134(1), 381-386. http://dx.doi.org/10.1016/j. foodchem.2012.02.191.

Valente, A., Albuquerque, T. G., Sanches-Silva, A., \& Costa, H. S. (2011). Ascorbic acid content in exotic fruits: a contribution to produce quality data for food composition databases. Food Research International, 44(7), 2237-2242. http://dx.doi.org/10.1016/j.foodres.2011.02.012. 